Brit. Heart J., 1965, 27, 691.

\title{
SPLITTING OF HEART SOUNDS FROM VENTRICULAR ASYNCHRONY IN BUNDLE-BRANCH BLOCK, VENTRICULAR ECTOPIC BEATS, AND ARTIFICIAL PACING*
}

\author{
BY \\ EDGAR HABER AND AUBREY LEATHAM \\ From the Cardiac Department, St. George's Hospital, London S.W.I \\ Received February 9, 1965
}

Asynchrony of ventricular contraction causes splitting of the first and second heart sounds which can be detected clinically in most normal subjects, and deviations from normal due to electrical or mechanical delays on one or other side of the heart have received much attention as valuable physical signs and in the understanding of hæmodynamics.

Electrical delays causing ventricular asynchrony and splitting of sounds occur first in bundlebranch block (Wolferth and Margolies, 1935), and secondly with ventricular ectopic beats; thirdly the advent of artificial pacing has made it possible to study splitting of sounds when the site of electrical stimulation of the heart has been known, and can be varied in the same patient during short intervals of time. For example, routine treatment of heart block may involve pacing from the cavity of the right ventricle by a catheter electrode (RV endocardium), and later, electrodes may be sewn on the surface of the right ventricle (RV epicardium), or the left ventricle (LV epicardium), and the splitting of heart sounds derived from these different points of stimulation can be studied and compared with natural beats to help our understanding of heart sounds and of the relation between electrical excitation and mechanical contraction.

\section{SubJeCts AND Methods}

Heart sounds were studied in 16 selected patients by means of a four-channel photographic recorder made by the Cambridge Instrument Company of England. Phonocardiograms from two sites, together with carotid pulse, respiration, and electrocardiogram were recorded simultaneously.

Electrocardiograms were interpreted to represent right or left bundle-branch block according to the usual criteria. In addition there was a third indeterminate group which could not be so classified. The aortic closure sound was identified by the dicrotic notch in the carotid pulse trace, an interval of 0.03 second being allowed for transmission delay. The relation between pulmonary and aortic closure sounds could usually be confirmed by comparing the amplitude of sound as recorded at the apex and the second left interspace, pulmonic closure being rarely detected at the apex.

Most of the patients studied were drawn from a group referred for treatment of heart block. Wherever possible, recordings were made before electrical pacing, after initiation of pacing via an endocardial catheter electrode, and finally after insertion of an implanted pacemaker with epicardial wires. Patients who had external stimulators could be studied with respect to both spontaneous and stimulated beats at the same sitting.

\section{RESULTS}

Heart Sounds in Conducted Beats with Bundle-branch Block and in Ventricular Ectopic Beats. In most cases of complete right bundle-branch block the onset of the right ventricular (RV) pressure

* Aided in part by Grant HE 06664 of the National Heart Institute. 


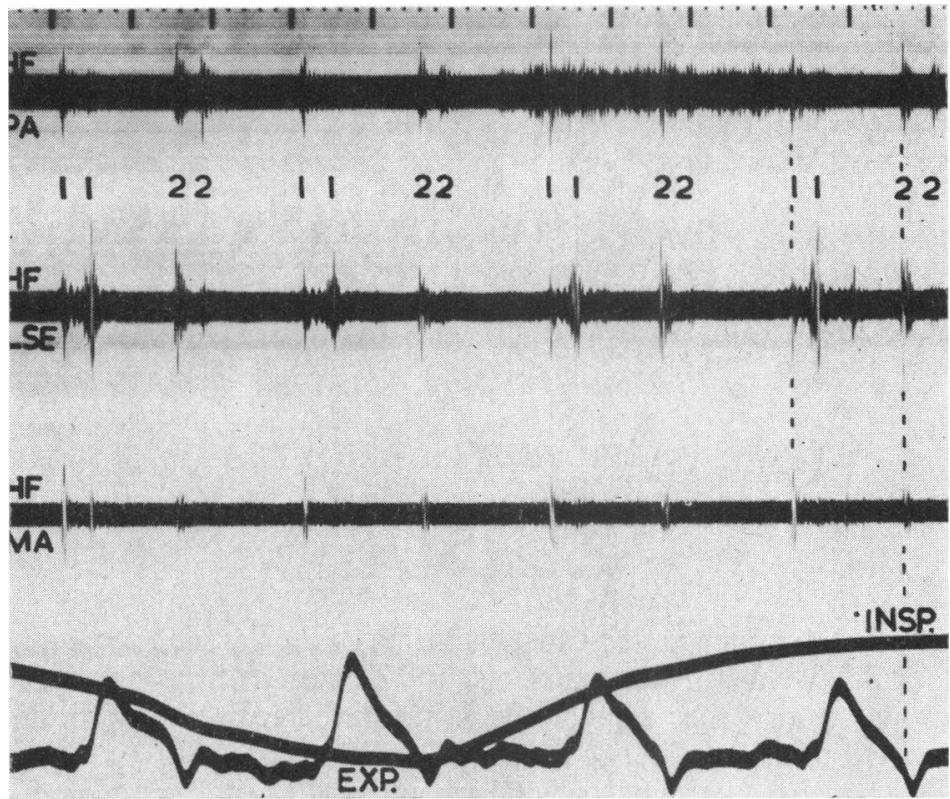

Fig. 1.-Complete right bundle-branch block demonstrating wide splitting of the first and second heart sounds, with mitral preceding tricuspid closure and aortic valve preceding pulmonic valve closure (physiological order). The time intervals in this and subsequent records are $0 \cdot 20$ and $0.04 \mathrm{sec}$. PA, pulmonary area; LSE, left sternal edge; MA, mitral area; HF, high frequency; EXP, expiration; INSP, inspiration.

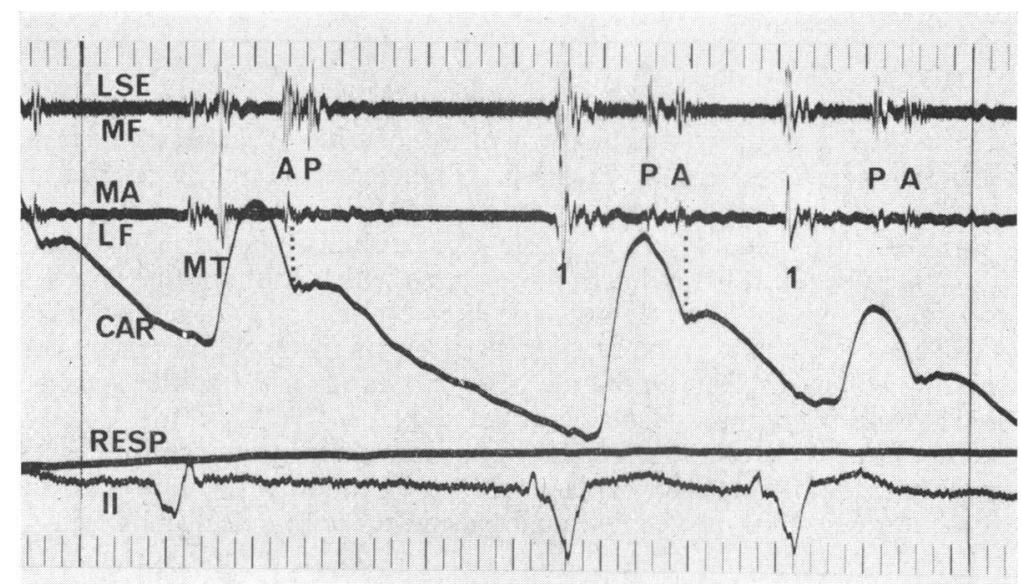

Fig. 2.-The first cycle illustrated is an ectopic beat arising in the left ventricle. The first and second sounds are widely split with mitral closure (M) preceding tricuspid closure $(T)$ and aortic valve (A) preceding pulmonic valve closure (P) (physiological order). The prevailing rhythm is atrial fibrillation with left-bundle block as illustrated in the second and third cycles. The first sound (1) is single and closure of the pulmonic valve precedes that of the aortic valve (reversed split). MF, medium frequency; LF, low frequency; CAR, carotid pulse; RESP, respiration; II, lead II of electrocardiogram. 
pulse is late, resulting in an increase of the normal slight right-sided delays so that tricuspid and pulmonary closure are late (Braunwald et al., 1956; Leatham and Gray, 1956), producing wide splitting of the first and second sounds (Fig. 1). Ectopic beats arising in the left ventricle (LV), and thus right bundle-branch block in pattern, have a similar effect on the 1st and 2nd heart sounds (Fig. 2). With partial right bundle-branch block (RSR in V1 and QRS less than $0.1 \mathrm{sec}$.), there is usually no delay in onset of the RV pressure pulse and no abnormal splitting of the 1st sound (Leatham and Gray, 1956). In most cases of complete left bundle-branch block the onset of the LV pressure pulse is not delayed (Coblentz et al., 1949), which could explain the absence of splitting of the 1st sound. The rise of pressure in the LV during the isometric period is, however, prolonged so that the carotid upstroke is late and aortic closure is delayed producing "reversed splitting" $\left(\mathrm{P}_{2}\right.$ before $\left.\mathrm{A}_{2}\right)$ of the second sound (Fig. 2) (Leatham, 1954). Thus it appears that most patients with left bundle-branch block really have left arborization block. We have seen only an occasional patient whose left bundle-branch block is associated with delayed onset of the LV pressure pulse as manifest by splitting of the 1st sound from delay in mitral closure. It is true, however, that there are not many patients with left bundle-branch block where the 1st sound can be studied, for it tends to be of low intensity, presumably because the atrio-ventricular valves have been semi-closed as a result of ventricular filling from powerful atrial contraction secondary to left ventricular disease or because of a slow rise of LV pressure. Ectopic beats of left bundle-branch block pattern, however, are frequently associated with reversed splitting of the 1 st sound as well as the second, reflecting protracted conduction from the ectopic focus in the RV to the LV (Fig. 3).

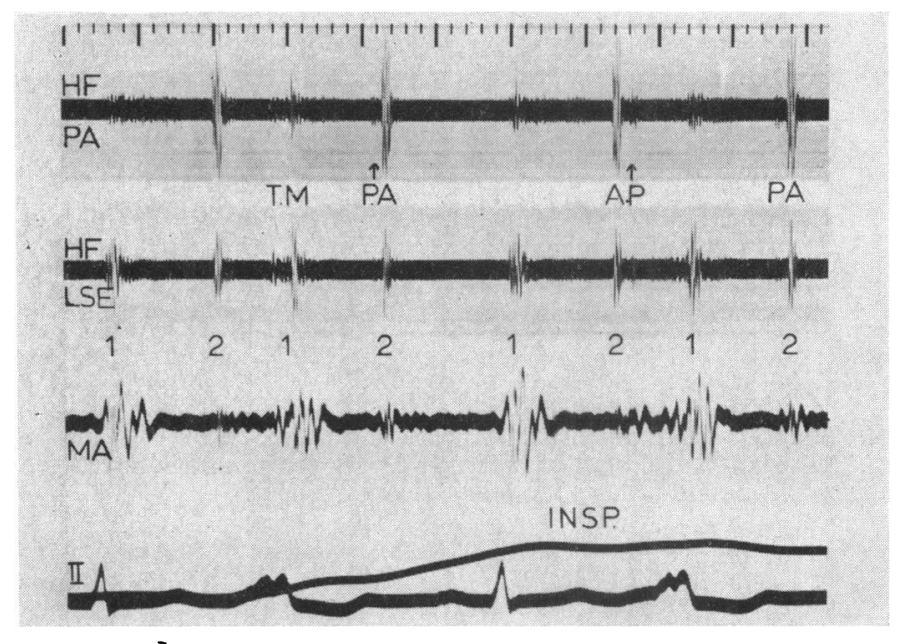

Fig. 3.-The third cycle is a conducted beat demonstrating physiological splitting (aortic valve closure preceding pulmonic valve closure) during inspiration (INSP). The second and fourth cycles occur as a result of ectopic beats originating in the right ventricle and causing reversed splitting of the first and second sounds. (Tricuspid closure precedes mitral closure and pulmonic closure precedes aortic closure.)

Heart Sounds in Paced Beats. Stimulation of the heart from a catheter in the RV (endocardial RV) or from an electrode on the RV (epicardial RV) in one patient produced a single 1st sound. It appears, therefore, that there was no delay in the onset of LV contraction even when the stimulus was in the right ventricle, though these observations were limited because the 1st.sound was usually of insufficient amplitude and clarity to be studied. There was, however, delay in the spread of conduction to the LV (as in left arborization block) as shown by a delay in the aortic component of the 2nd sound ("reversed split") (Fig. 4 and 5). 


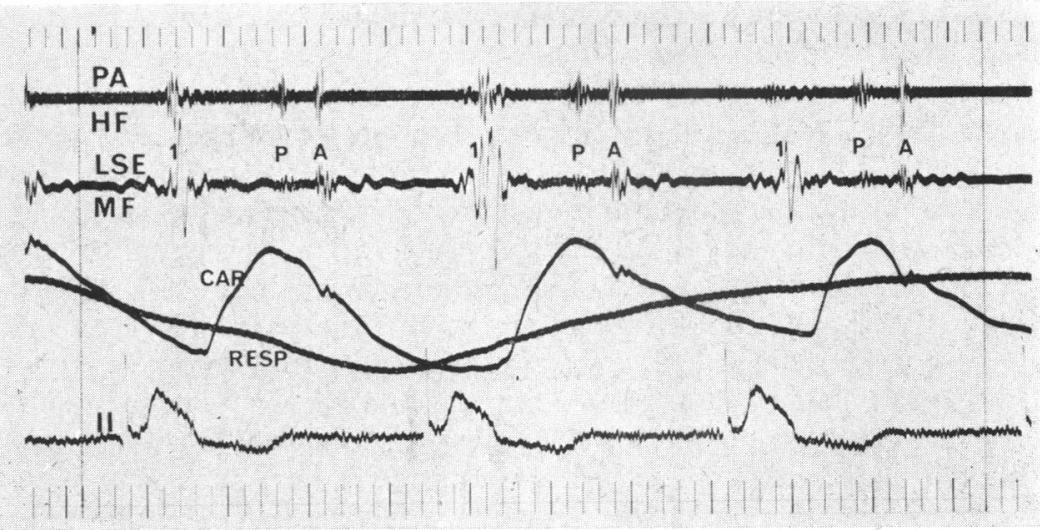

FIG. 4.-Electrical pacing from the right ventricular cavity. The first sound is single and the second sound widely split, with the pulmonic component preceding the aortic component ("reversed" splitting).

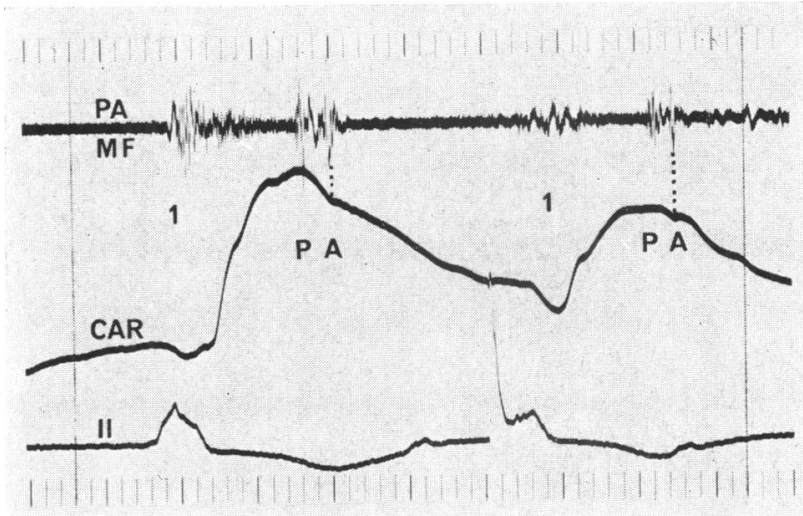

FIG. 5.-Spontaneous beat arising in right ventricle followed by paced beat from right ventricular cavity. In both instances the onset of the carotid pulse wave is not delayed yet the aortic component of the second sound follows the pulmonic component.

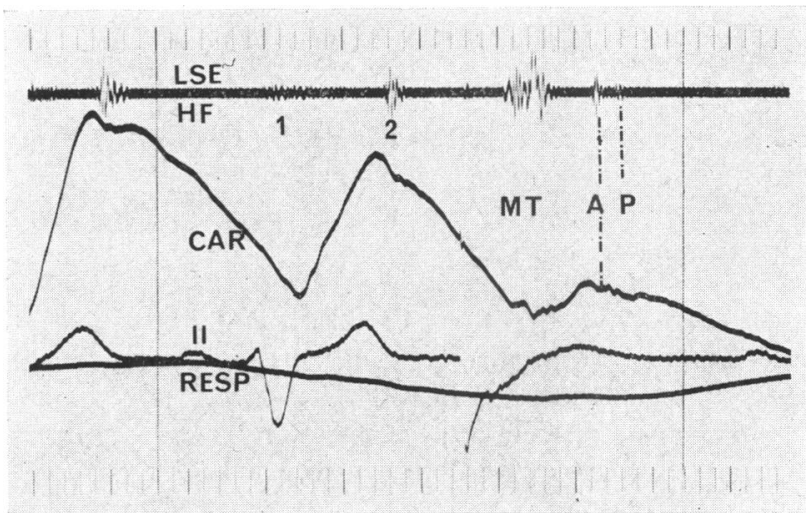

FIG. 6.-A conducted beat originating in the sinus node followed by a cycle resulting from electrical pacing of the left ventricular epicardium. Both first and second sounds of the latter cycle are widely split with mitral preceding tricuspid closure, and aortic valve preceding pulmonic valve closure (physiological order). 
TABLE

\begin{tabular}{|c|c|c|c|}
\hline Patient & Site of pacing & Complex & Second sound \\
\hline 1 & LV surface & RBBB & Physiological order \\
\hline 2 & LV surface & RBBB & Physiological order \\
\hline 3 & $\begin{array}{l}\text { Spontaneous beat } \\
\text { RV cavity }\end{array}$ & $\begin{array}{l}\text { LBBB } \\
\text { LBBB }\end{array}$ & $\begin{array}{l}\text { Reverse split } \\
\text { Reverse split }\end{array}$ \\
\hline 4 & Spontaneous beat & RBBB & Physiological order \\
\hline & LV surface & RBBB & Physiological order \\
\hline 5 & LV surface & $?$ & Physiological order \\
\hline 6 & $\begin{array}{l}\text { Spontaneous beat } \\
\text { RV cavity }\end{array}$ & $\begin{array}{l}\text { LBBB } \\
\text { LBBB }\end{array}$ & $\begin{array}{l}\text { Reverse split } \\
\text { Reverse split }\end{array}$ \\
\hline 7 & Spontaneous beat & RBBB & Physiological order \\
\hline & RV cavity & LBBB & Reverse split \\
\hline 8 & $\begin{array}{l}\text { Spontaneous beat } \\
\text { RV cavity }\end{array}$ & $\begin{array}{l}\text { RBBB } \\
\text { LBBB }\end{array}$ & $\begin{array}{l}\text { Physiological split } \\
\text { Reverse split }\end{array}$ \\
\hline 9 & RV cavity & LBBB & Reverse split \\
\hline & spontaneous beat & LBBB & Reverse split \\
\hline 10 & LV surface & $?$ & Physiological order \\
\hline 11 & $\begin{array}{l}\text { Spontaneous beat } \\
\text { RV surface }\end{array}$ & $\begin{array}{c}\text { RBBB } \\
?\end{array}$ & $\begin{array}{l}\text { Physiological order } \\
\text { Reversed split }\end{array}$ \\
\hline 12 & $\begin{array}{l}\text { Spontaneous beat } \\
\text { Coronary sinus } \\
\text { RV cavity }\end{array}$ & $\begin{array}{c}\text { RBBB } \\
? \\
?\end{array}$ & $\begin{array}{l}\text { Physiological order } \\
\text { Physiological order } \\
\text { Reverse split }\end{array}$ \\
\hline 13 & $\begin{array}{l}\text { Spontaneous beat } \\
\text { RV cavity } \\
\text { LV surface }\end{array}$ & $\begin{array}{c}\text { LBBB } \\
? \\
?\end{array}$ & $\begin{array}{l}\text { Reversed order } \\
\text { Reversed order } \\
\text { Physiological order }\end{array}$ \\
\hline 14 & $\begin{array}{l}\text { Spontaneous beat } \\
\text { RV cavity }\end{array}$ & $\begin{array}{l}\text { LBBB } \\
\text { LBBB }\end{array}$ & $\begin{array}{l}\text { Reversed order } \\
\text { Reversed order }\end{array}$ \\
\hline 15 & $\begin{array}{c}\text { Simultaneous pacing } \\
\text { of } R V \text { and } L V\end{array}$ & $?$ & $\begin{array}{l}\text { Physiological split which } \\
\text { closes on expiration }\end{array}$ \\
\hline 16 & RV cavity & $?$ & Reversed order \\
\hline
\end{tabular}

Stimulation of the heart from an electrode on the surface of the LV (LV epicardium) produced wide splitting of both 1 st and 2 nd sounds due to right-sided delay (late tricuspid and pulmonary closure: Fig. 6). Here again observations could only be made on the 1 st sound in a few cases. In one patient the heart was stimulated from a catheter thought to be in a coronary vein over the LV, and there was right-sided delay similar to the effect of stimulation from an electrode on the surface of the LV. The catheter was then withdrawn to the cavity of the right ventricle and this reversed the order of the sounds (left-sided delay). In one patient with electrodes in parallel on the RV and LV, the heart sounds were normal as expected since the ventricles must have been contracting simultaneously.

The Table summarizes the relationship of the site of pacing to the order of the two components of the 2 nd sound in 16 patients studied.

\section{Discussion}

Splitting of the 1st and 2nd heart sounds can be detected during respiration in most normal subjects and is due to slight asynchrony of ventricular contraction. Our understanding of splitting of sounds and ventricular asynchrony from electrical delays can be increased by studying the heart sounds in bundle-branch block, ventricular ectopic beats, and during artificial pacing when the site of the stimulus can be made to vary. Conducted right bundle-branch block, ectopics arising from the LV, and LV epicardial pacing are associated with delay in tricuspid and pulmonary valve closure as expected.

With conducted left bundle-branch block and endocardial or epicardial RV pacing, we were surprised to find no delay in mitral closure, though aortic closure was delayed as expected. It appears that the cardiographic pattern of left bundle-branch block is usually an arborization block and some fibres of the bundle must remain intact, preventing delay in the onset of ventricular contraction, 
though the later spread of activation must be slow. Again, with artificial pacing from the cavity of the RV, early activation of the LV appears to take place but the spread of the impulse must be slowed to cause delay in carotid upstroke and $A_{2}$. Yet natural ectopic beats arising from the right ventricle (of left bundle-branch block pattern) may be associated with delay in activation of the LV as shown by delay in mitral closure.

It is interesting that right bundle-branch block apparently causes delay in onset of contraction of the RV but left bundle-branch block does not cause delay in contraction of the LV. This may be due to differences in anatomy between the right and left bundle - the right remaining single for much of its length, the left arborizing soon after the bifurcation of the bundle. The localized nature of the right bundle must make it more susceptible to complete interruption. Indeed in isolated disease of the conducting tissue (Stokes-Adams disease) right bundle-branch block rather than left is the rule (Portal et al., 1962).

Thus the study of changes in mechanical events as shown by splitting of sounds has helped the understanding of abnormalities of electrical conduction, which in turn has helped to confirm present ideas on the origin of the components of the first and second heart sounds. During artificial pacing the site of the stimulating electrode can often be placed by auscultation, and this is sometimes of practical value.

\section{SUMMARY}

Delay in electrical activation of the right ventricle from left ventricular ectopic beats, conducted right bundle-branch block, and artificial pacing from the epicardium of the left ventricle, all cause wide splitting of the first and second heart sounds from delay in tricuspid and pulmonary closure.

Delay in electrical activation of the left ventricle from right ventricular ectopic beats causes delay in mitral and aortic closure which can be detected on auscultation as reversed splitting of both first and second sounds. It would be expected that conducted left bundle-branch block, and pacing from the right ventricle, would produce similar left-sided delays, and while this was true for the second sound, no reversed splitting of the first sound could be demonstrated. It appears that the onset of left ventricular activation is seldom delayed and it is suggested that this is related to the early aborization of the left bundle.

These findings support present ideas on splitting of the first and second heart sounds and have some practical significance.

\section{REFERENCES}

Braunwald, E., Donoso, E., Sapin, S. O., and Grishman, A. (1956). Right bundle-branch block. Hemodynamic, vectorcardiographic and electrocardiographic observations. Circulation, 13, 866.

Coblentz, B., Harvey, R. M., Ferrer, M. I., Cournand, A., and Richards, D. W., Jr. (1949). The relationship between electrical and mechanical events in the cardiac cycle of man. Brit. Heart J., $11,1$.

Leatham, A. (1954). Splitting of the first and second heart sounds. Lancet, 2, 607.

- , and Gray, I. (1956). Auscultatory and phonocardiographic signs of atrial septal defect. Brit. Heart J., 18, 193.

Portal, R. W., Davies, J. G., Leatham, A., and Siddons, A. H. M. (1962). Artificial pacing for heart-block. Lancet, 2, 1369.

Wolferth, C. C., and Margolies, A. (1935). Asynchronism in contraction of the ventricles in so-called common type of bundle-branch block. Amer. Heart J., 10, 425. 